Review Article

\title{
Recent Advances in Stimuli-Responsive Photofunctional Materials Based on Accommodation of Chromophore into Layered Double Hydroxide Nanogallery
}

\author{
Wu Li, Dongpeng Yan, Rui Gao, Jun Lu, Min Wei, and Xue Duan \\ State Key Laboratory of Chemical Resource Engineering, Beijing University of Chemical Technology, Beijing 100029, China \\ Correspondence should be addressed to Dongpeng Yan; yandongpeng001@163.com
}

Received 29 October 2012; Accepted 27 December 2012

Academic Editor: Su Chen

Copyright (C) $2013 \mathrm{Wu} \mathrm{Li}$ et al. This is an open access article distributed under the Creative Commons Attribution License, which permits unrestricted use, distribution, and reproduction in any medium, provided the original work is properly cited.

\begin{abstract}
The assembly of photofunctional molecules into host matrices has become an important strategy to achieve tunable fluorescence and to develop intelligent materials. The stimuli-responsive photofunctional materials based on chromophores-assembled layered double hydroxides (LDHs) have received much attention from both academic and industry fields as a result of their advantages, such as high photo/thermal stability, easy processing, and well reversibility, which can construct new types of smart luminescent nanomaterials (e.g., ultrathin film and nanocomposite) for sensor and switch applications. In this paper, external environmental stimuli have mainly involved physical (such as temperature, pressure, light, and electricity) and chemical factors (such as $\mathrm{pH}$ and metal ion); recent progress on the LDH-based organic-inorganic stimuli-responsive materials has been summarized. Moreover, perspectives on further development of these materials are also discussed.
\end{abstract}

\section{Introduction}

The functional material that can respond to different external stimuli is the basis for developing a new generation of intelligent device. Stimuli-responsive organic photofunctional (such as luminescent) materials have attracted significant attention from both fundamental research as well as industry during the last few years, because of their remarkable and sensitive response signal. These photofunctional materials have potential applications in the fields of fluorescent switches and optical recording sensors [1]. Generally, the mechanisms for changing in photofunction of organic materials consist of occurrence of chemical reactions and alteration of the molecular packing mode $[2,3]$. Recently, controlling and tuning the molecular packing mode become a main strategy for the design of intelligent luminescent materials, because the solid-state chemical reaction frequently involves relatively low conversion efficiency. Since 2005, several new types of organic luminescent materials with stimuli-responsive properties (such as piezochromic, deformation-induced chromic, photochromic, thermochromic, and humidity colorimetric luminescent systems) have been developed [4-7]. However, to meet the requirements of responsive luminescent devices or optical sensors, the assembly of ordered thin films with the chromophores on two-dimensional (2D) surfaces remains a challenge, and examples are rather rare.

For an idealized orderly system, the photoactive molecules with regular molecular orientation and intermolecular packing mode are more prone to exhibit systematically responsive behaviors upon external stimuli. Therefore, the control of high orientation of organic molecules is of critical importance to design and fabricate responsive luminescent materials. As well, from a perspective of luminescent efficiency, the aggregates of luminescent molecules are usually readily formed in the solid state, which can lead to an emission shift, line broadening, and even luminescence quenching. Moreover, the thermal/chemical stability and service lifetime of organic materials are generally low for optoelectronic device application [8]. Therefore, how to further enhance the optical performance and stability also became major goals. In addition, from a viewpoint of practical application, fast response, high reversibility, and stable repeatability are all necessary for such responsive materials as sensors and switches. 


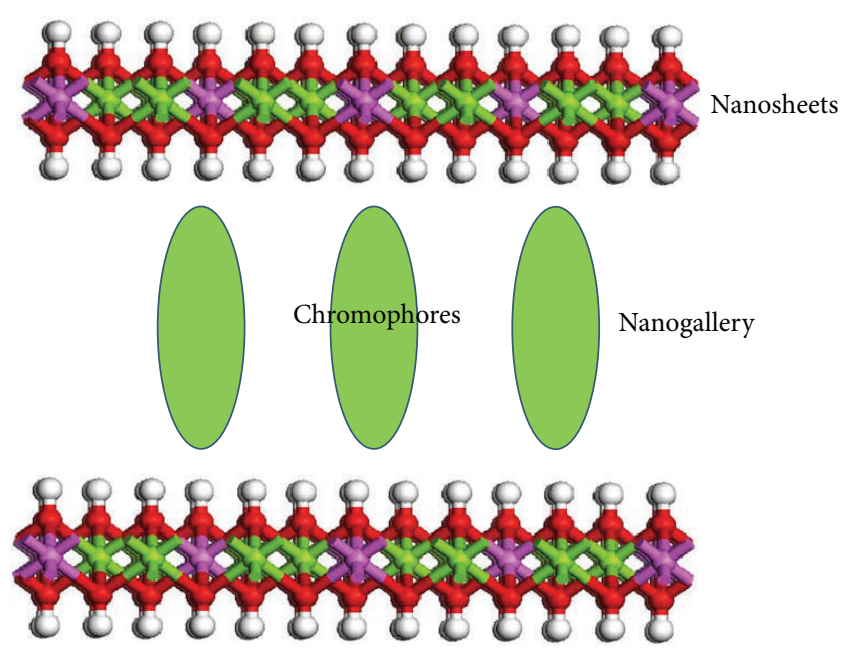

Figure 1: A typical scheme for chromophores assembled into $\mathrm{Mg}$ Al-LDH nanogallery.

One effective way to realize the regulation and orientation of the organic chromophores is the incorporation of organic photofunctional molecules into solid host matrices, which can also supply a stable environment to enhance the thermo and photostabilities of organic species. In this sense, layered double hydroxides (LDHs) are typical layered host materials, which can be described by the general formula: $\left[\mathrm{M}^{\mathrm{II}}{ }_{1-x} \mathrm{M}^{\mathrm{III}}{ }_{x}(\mathrm{OH})_{2}\right]^{z+} A^{n-}{ }_{z / n} \cdot y \mathrm{H}_{2} \mathrm{O}\left(\mathrm{M}^{\mathrm{II}}\right.$ and $\mathrm{M}^{\mathrm{III}}$ are divalent and trivalent metals ions, respectively; $\mathrm{A}^{n-}$ is an anion) [9]. The structure of the LDH layer is analogous to that of the brucite with edge-sharing $\mathrm{M}(\mathrm{OH})_{6}$ octahedra, in which partial substitution of $\mathrm{M}^{3+}$ for $\mathrm{M}^{2+}$ induces positively charged host layers, balanced by the interlayer anions. Different from most of the cationic clays, the charge density and elemental composition of LDHs can be changed during the synthesis process, favoring finely controlling properties of the host layer. To meet the demands in applications, hundreds of suitable anions have been rationally chosen and intercalated into LDHs for constructing new types of host-guest nanomaterials [10].

The LDH features 2D channel at the nanometer level, and the nanogallery is usually in the range of $0.3-4 \mathrm{~nm}[11]$; therefore, most of anionic organic photoactive guests can be incorporated into LDH hosts to obtain inorganic-organic hybrid nanomaterials (as shown in Figure 1). These systems show specific physical and chemical performances compared with their individual counterparts, which is beneficial for the fabrication of novel optoelectronic and photofunctional materials: (1) chromophore guest molecules immobilized in the LDH host matrix exhibit optical and thermal stability, environmental compatibility, and low operational risk [12]. (2) The orientation and arrangement of the chromophores can be tuned by changing the layer charge density and chemical composition, which can further adjust the optical properties of the nanocomposites [13, 14]. (3) LDH host matrix provides chromophore molecules with a confined and stable environment, which reduces molecular thermal agitation (intermolecular collisions, vibrations, and rotations) by host-guest interactions, and the fluorescence quenching is therefore reduced $[15,16]$. Recently, according to the principle of molecular design and supramolecular assembly, the inorganic-organic nanomaterials (both powders and thin films) based on the accommodation of chromophore guests into LDH host have been largely developed and have gradually become a fascinating field in luminescent hybrid materials $[17,18]$. For example, the polyanion-assembled LDH films exhibit a better UV light resistance ability than the pure polyanion/polycation film. By the use of in-situ photoluminescence technique, [15] it was found that the normalized fluorescence intensity of the anionic poly $(p$ phenylene) (APPP) assembled LDH was larger than that of the APPP/PDDA (poly(dimethyldiallylammonium chloride)) counterpart, demonstrating that the presence of the inorganic LDH nanosheets leads to an enhanced optical stability of the conjugated anions compared with typical organic/organic films. A previous review on LDH-based fluorescent materials has mainly summarized the preparation method and tunable photoluminescent properties [19]. Recently, the host-guest stimuli-responsive luminescent materials have also been studied successively, since the orientation mode of the interlayer chromophores and hostguest interaction can be changed upon external stimuli [20, 21]. In addition, new physical/chemical phenomena have also been obtained based on the theoretical calculations for these hybrid nanomaterials. We believe it is timely and necessary to introduce these new advances to give a better understanding and supply new insights for the design of organicinorganic intelligent nanomaterials. In this paper, we focus our attention on recent progress of the stimuli-responsive photofunctional materials for optical/luminescent switch and sensor applications by assembling photofunctional molecules into LDH nanogallery; by selecting representative stimuliresponsive examples, two types of environmental stimuliphysical stimuli (such as light, pressure, heat, electricity and polarization) and chemical stimuli $(\mathrm{pH}$ value and heave metal ions)-were mainly introduced. Finally, perspectives on future development for these materials are also discussed.

\section{LDH-Based Physical Stimuli-Responsive Materials}

2.1. Heat- and Pressure-Responsive Materials. Temperature and pressure are the most common and natural enviremental factors; therefore, temperature- and pressure-induced chromic (known as thermochromic and piezochromic) materials can be potentially used in memory chips and security inks. Stilbene-type compounds have attracted considerable interests due to their excellent optical and electronic properties [22, 23]. Yan et al. [24] have fabricated an inorganic-organic ultrathin film (UTF) system with thermochromic luminescence (TCL) based on the layer-by-layer (LBL) assembly of anionic stilbene derivative (bis(2-sulfonatostyryl)biphenyl, donated as BSB) and LDH nanosheets. The thickness of the BSB/LDH UTF can be 
finely controlled in the range from $23 \mathrm{~nm}$ ( 8 bilayers) to $67 \mathrm{~nm}$ (32 bilayers), indicating that the average thickness of one $\mathrm{BSB} / \mathrm{LDH}$ unit is about $2.2 \mathrm{~nm}$. The UTF undergoes a remarkable change in luminescence color upon increasing temperature. On heating the $\mathrm{BSB} / \mathrm{LDH}$ from 20 to $100^{\circ} \mathrm{C}$, the emissive band moves from 444 to $473 \mathrm{~nm}$ with a gradual decrease in the luminescence intensity. The emission color changes from blue to bluish green on heating the UTF, and the color change is also visible to the naked eye as shown in the inset of Figure $2(\mathrm{a})$. When the UTF was cooled to $20^{\circ} \mathrm{C}$ over $2 \mathrm{~min}$, the fluorescence emission can recover its original blue color completely together with the associated reverse spectral changes. The reversible change in luminescence color can also be repeated (Figure 2(a), inset). For the excited states of the UTF, the fluorescence decay at high temperature is slower than that at low temperature (Figure 2(b)), and this behavior can be assigned to the formation of an excimer in the UTF. The fluorescence lifetime of the UTFs at $100^{\circ} \mathrm{C}$ is $1.9 \mathrm{~ns}$, about twice the value at $20^{\circ} \mathrm{C}(0.9 \mathrm{~ns})$. These changes in fluorescence lifetime are repeatedly observed on cycling between two typical temperatures (Figure 2(b), inset).

In-situ FTIR measurement shows that, as the temperature increases, the most significant change is that the bands at 1652 and $1630 \mathrm{~cm}^{-1}$ broaden and become unresolved for the UTF, suggesting that the skeleton vibration increases dramatically at high temperature and the system becomes relatively disordered compared with that at low temperature. No characteristic band disappears in the whole range, demonstrating no chemical reaction occurs during the heating process. Further molecular dynamic simulation confirms that the TCL performance is mainly associated with the variations in orientation and molecular packing of BSB confined between the LDH nanosheets. Based on TCL performance, it is anticipated that the UTFs can be potentially used as luminescent sensors and molecular thermometers.

The study on the reversible thermochromic materials has attracted more attention due to its wide applications such as optical data storage, security markers for notes and documents, and color-variable clothing [26]. 4-(4-anilinophenylazo)benzenesulfonate (AO5) is a typical azo dye with thermochromic property, which has been used as a thermal sensor, $\mathrm{pH}$ indicator, and molecular memory storage due to its tautomerism between the azo A form and hydrazone $\mathrm{H}$ form (Figure 3). Such tautomeric equilibrium is sensitive to the external microenvironment (e.g., substituents and solvents). An effective way to enhance the thermochromic performances of this dye is to choose a suitable host matrix for tuning its molecular environment. Wang et al. [25] have fabricated transparent thin films based on AO5 and sodium dodecylbenzene sulfonate (SDS) cointercalated in LDH, which show a fast and repeatable thermochromic behavior. By the use of temperature-dependent UV/visible absorption spectrophotometer, it was observed that the $10 \%$ AO5-LDH thin film shows the highest thermochromic efficiency.

At ambient temperature, the AO5-LDH thin film has a maximal absorption at $363 \mathrm{~nm}$ (Figure 4(a)). Upon increasing temperature, a spectral change occurs with a decrease in the intensity of the band at $363 \mathrm{~nm}$, and a new band appears with increasing intensity at $445 \mathrm{~nm}$. Visually, a color change from light yellow to reddish orange can be observed upon heating the $10 \%$ AO5-LDH film from 35 to $65^{\circ} \mathrm{C}$. As the film is cooled to $35^{\circ} \mathrm{C}$, it recovers its original color with the associated converse spectral changes. Figure 4(b) shows the temperature-dependent absorbance at $445 \mathrm{~nm}$ over a complete heating-cooling cycle, confirming the reversibility of the thermochromic performance. Moreover, the film material also shows high thermostability and photostability as a result of the host-guest structure. As the temperature range for the thermochromism covers the body temperature of human beings and the atmosphere, it can be expected that this AO5-LDH film has potential applications in the field of physiological and environmental temperature designation and warning.

Conjugated polydiacetylenes (PDAs) have attracted great attention during the past few years, owing to their significant functionality and wide applicability in colorimetric detection systems $[27,28]$. It is highly desirable to achieve sensor and array devices with high stability, reusability, and environmental compatibility by the immobilization of PDAs. Recently, Shi et al. [29] have prepared the 1,3-diacetylene (DA) anion-intercalated LDH nanocomposite films with the aid of a photolithography technique. UV irradiation of the colorless DA-LDH film results in the formation of patterned blue/colorless image (Figure 5(a) A, B). Heating the film at $130^{\circ} \mathrm{C}$ results in the transition to yellow/colorless patterned image, while it transfers to red/colorless patterned image as the film is cooled down (Figure 5(a) C, D). The heat-treatment at $130^{\circ} \mathrm{C}$ shows an orange-yellow/colorless fluorescence image, which displays a bluish green/colorless fluorescence image when the sample is cooled (Figure 5(b) C, D). For the corresponding film with physical mixture of PDA and LDH, no thermal response can be observed for optical image. By the analysis of in-situ Raman spectroscopy, the thermochromic behavior of $\mathrm{PDAs} / \mathrm{LDH}$ is attributed to strong hydrogen bond interactions between $\mathrm{LDH}$ and PDAs.

To date, compared with those of temperature-sensitive materials, the study of piezochromic luminescence (PCL) materials remains in an early stage [30]. The design of PCL materials is of importance to monitor the change in pressure, especially under extreme conditions. It has been recognized that alternating the molecular arrangement mode is a promising strategy to tune the fluorescence of an organic compound. During last 10 years, efforts have been put in the development of pure organic fluorophores with PCL properties, and these materials usually involve an aggregationinduced emission mechanism [31, 32]. However, the rational design and preparation of organic-inorganic hybrid PCL materials remain a considerable challenge.

Recently, we have fabricated a new type of PCL material by the assembly of an organic fluorophore $\left(2,2^{\prime}\right.$ - $(1,2$-ethenediyl)bis[5-[4-(diethylamino)-6-[(2,5-disulfophenyl)amino]-1,3,5-triazin-2-yl] amino] benzene sulfonate anion, BTZB) into the nanogalleries of LDHs [33]. Such strategy for construction of PCL material is based on the fact that the $\mathrm{LDH}$ nanosheets are flexible enough to deform over interlayer bulky guests, and slipping of $\mathrm{LDH}$ layer can occur 


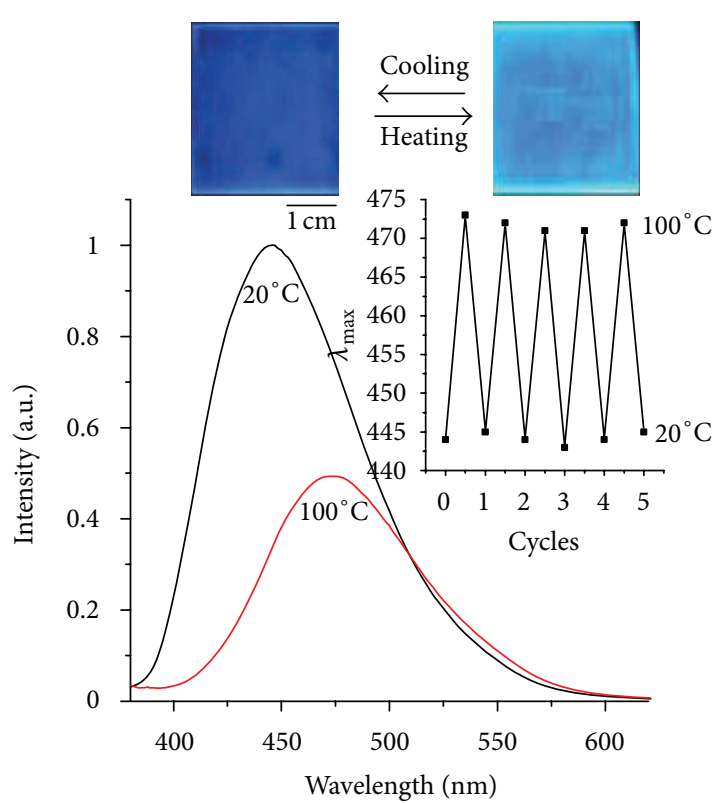

(a)

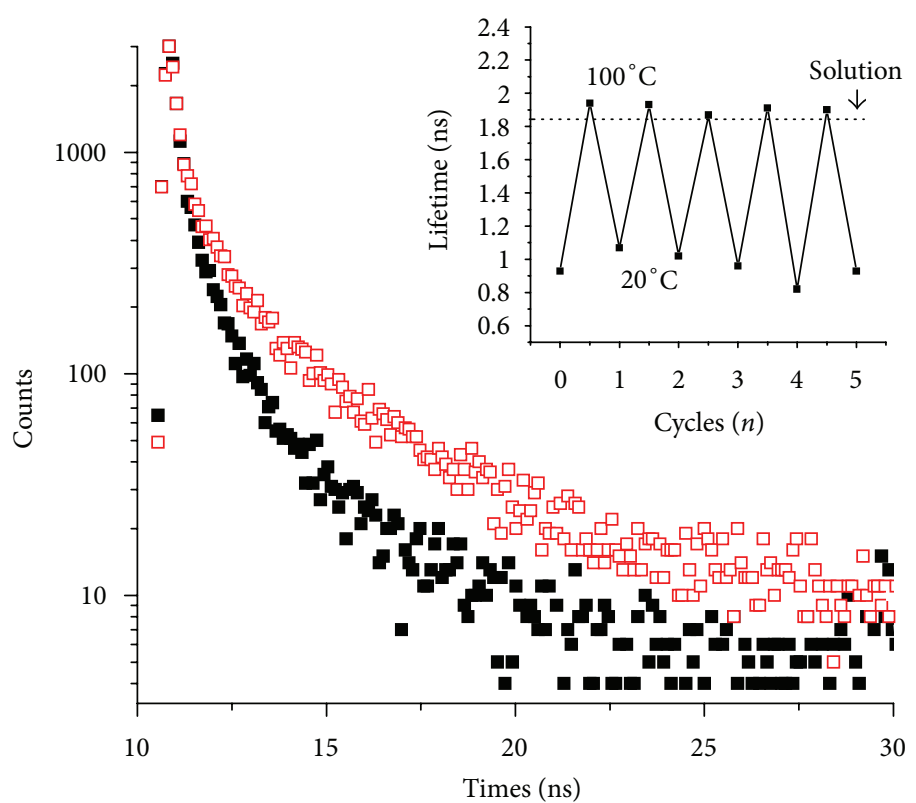

$20^{\circ} \mathrm{C}$ $100^{\circ} \mathrm{C}$

FIGURE 2: TCL of the BSB/LDH UTF at 20 and $100^{\circ} \mathrm{C}$. (a) Fluorescence spectra (inset: the reversible fluorescence response over five consecutive cycles, and photographs of the UTF before and after heating). (b) Fluorescence decay curve (inset: fluorescence lifetimes over five consecutive cycles) [24].

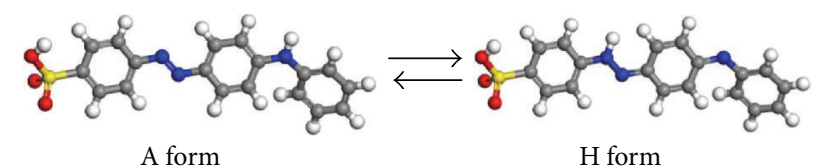

FIgURE 3: Tautomeric equilibrium between the $\mathrm{A}$ form and $\mathrm{H}$ form of $\mathrm{AO} 5$ [25].

on increasing the external pressure, which can further influence the host-guest interactions [21]. In addition, the long-chain BTZB anion has four rotatable aromatic amine units, and thus its molecular conformation and intermolecular interactions can be tuned more easily by external perturbations than the rigid molecules. Upon increasing pressure, $\mathrm{BTZB} / \mathrm{LDH}$ nanocomposites exhibit luminescent redshift with a concomitant broadening of the emission, while the pristine BTZB shows no PCL at all. The most significant PCL behavior is present in the $\mathrm{BTZB} / \mathrm{Mg}_{2} \mathrm{Al}-\mathrm{LDH}$ sample, and the maximum emissive wavelength moves from 452 to $515 \mathrm{~nm}$ under different stimuli (Figures 6(a) and 6(b)). The typical photographs of the $\mathrm{BTZB} / \mathrm{Mg}_{2} \mathrm{Al}-\mathrm{LDH}$ pellet under UV light (Figure 6(a), inset) display a visual luminescent change from blue to green upon increasing pressure. The redshift of spectra may be attributed to the formation of $J$-type aggregates in the nanogallery of LDH. An appreciable change in the UV-vis absorption band of $\mathrm{BTZB} / \mathrm{Mg}_{2} \mathrm{Al}-\mathrm{LDH}$ nanocomposites was also observed upon compression as shown in Figure 6(c).
Once the pressed $\mathrm{BTZB} / \mathrm{Mg}_{2} \mathrm{Al}-\mathrm{LDH}$ sample was ground into powder, heated at $100^{\circ} \mathrm{C}$, and then cooled down, the luminescent peak at $515 \mathrm{~nm}$ moved back to $452 \mathrm{~nm}$ completely. In addition, the reversible luminescent color change can be readily repeated to switch between two pressures. The reversible changes in fluorescence properties can be recycled at least 3 times. Therefore, it can be concluded that the BTZB-intercalated LDH material exhibits reversible optical responses (luminescent color, absorption band, and fluorescent lifetime) upon changing external pressure; molecular dynamics and periodic density functional theoretical studies demonstrate that the PCL performance originates from changes in the relative orientation and aggregation state of the interlayer BTZB. Such materials may serve as the fluorescent antiforgery devices.

2.2. Photoinduced-Responsive Materials. The photoinduced cis-trans isomerization of organic photofunctional materials (such as Schiff base and azobenzene derivative) has presented many interesting features, and their applications range from electronics to nonlinear devices [34-37]. In the solid state of these materials, the penetration between adjacent functional group and strong $\pi-\pi$ stacking of chromophores may lead to a lack of sufficient free volume for the isomerization and lead to irreversibility or low efficiency of the process. This is one of the main bottlenecks in developing optical devices with superior optical properties based on the molecular isomerization. $\mathrm{LDH}$ nanosheets can provide the organic 


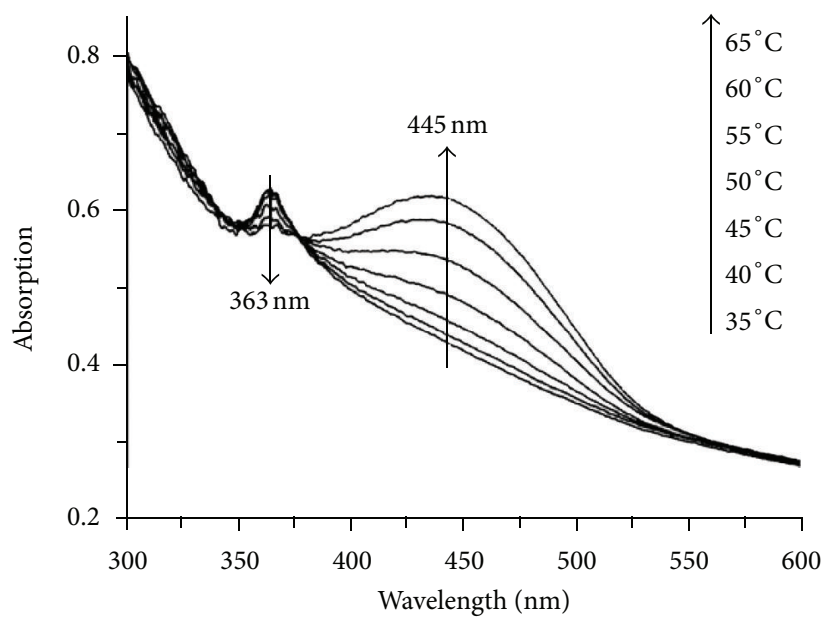

(a)
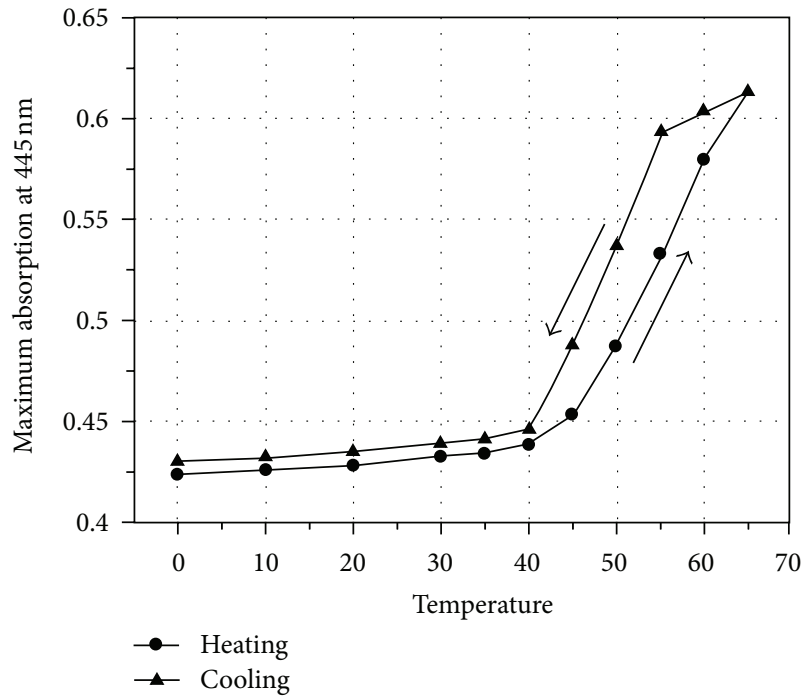

(b)

FIgURE 4: (a) In-situ absorption spectra of the 10\% AO5-LDH film during heating in the temperature range $35-65^{\circ} \mathrm{C}$. (b) The correlation between the absorbance of the band at $445 \mathrm{~nm}$ and temperature over a heating-cooling cycle [25].
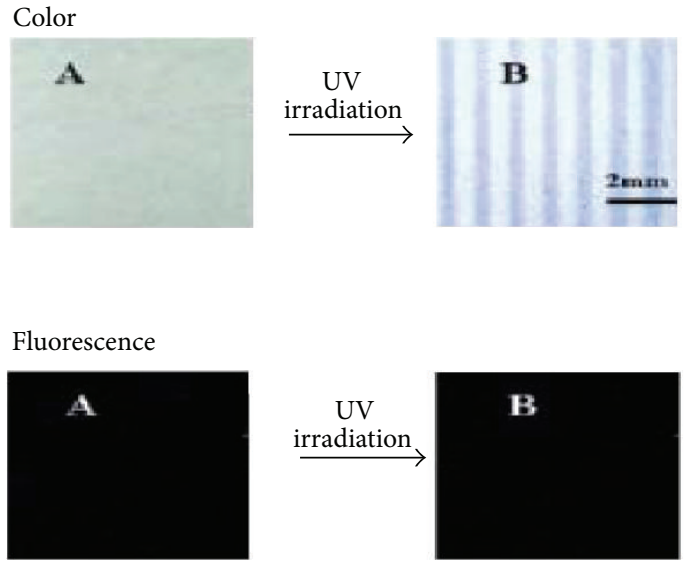

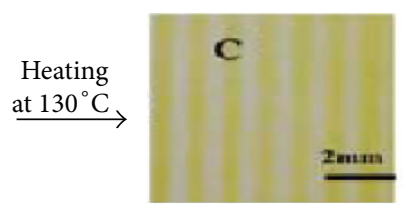

(a)
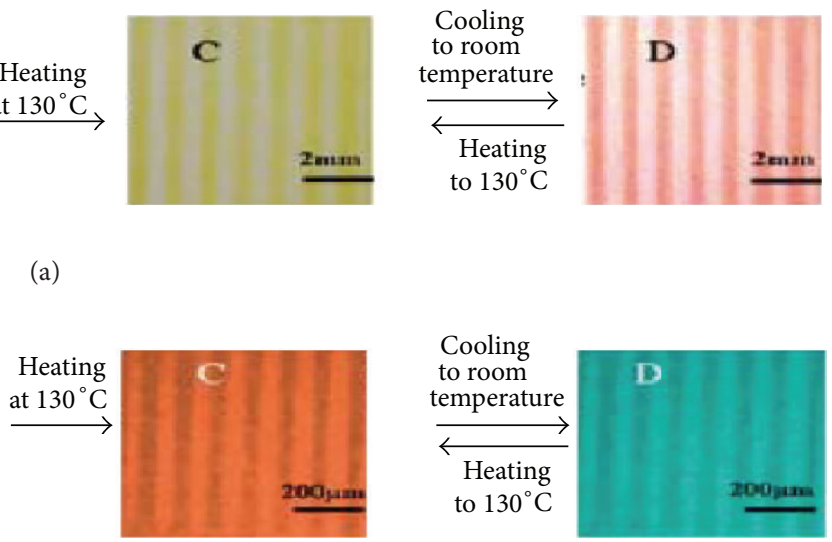

(b)

FIgURE 5: PDA-LDH film induced by UV irradiation and its thermochromic behavior (a) and fluorescent transition (b): (A) the DA-LDH film, (B) the PDA-LDH film obtained by UV irradiating (A), (C) the film by heating (B) at $130^{\circ} \mathrm{C}$ for $1 \mathrm{~min}$, (D) the film by cooling (C) to room temperature [29].

chromophores with a rigid and ordered microenvironment, in which the severe interpenetration of the cis-trans groups may be restrained by the isolating effect of the $2 \mathrm{D}$ nanosheets. An ordered distribution and alignment of the cis-trans groups with sufficient available free space in the nanogallery between the LDH nanosheets can also facilitate their photoisomerization efficiency. In pioneering works, Tagaya et al. [38-40] have prepared sulfonated indolinespirobenzopyran (SP) intercalated into the $\mathrm{Mg} / \mathrm{AI}$ and $\mathrm{Zn} / \mathrm{Al} \mathrm{LDHs}$, which was premodified by toluene- $p$-sulfonic acid (PTS). The new intercalated nanocomposites exhibited reversible photoisomerization between SP and merocyanine (MC) as shown in the Figure 7. It was also noted that the presence of PTS play a key role in the reversible photoisomerization.
Han et al. [41] have reported the fabrication of hybrid ultrathin photoresponsive films based on LBL self-assembly of LDH nanosheets and the azobenzene-containing polymer (PAZO). By irradiating the sample with UV light, there is a progressive decrease in the maximum intensity of $\pi-\pi^{*}$ transition band, and the $\pi-\pi^{*}$ band nearly disappears after sufficient irradiation time, indicating an almost $100 \%$ transto-cis photoreaction. The $\pi-\pi^{*}$ absorption band increases again with irradiation by visible light $(\lambda>450 \mathrm{~nm})$, indicative of the cis-trans back-isomerization of azobenzene. Furthermore, alternate irradiation with UV and visible light results in a reversible switching between the trans- and cis-state of the azobenzene group with significant changes in film color. The thin film of azobenzene derivative-intercalated $\mathrm{LDH}$ 


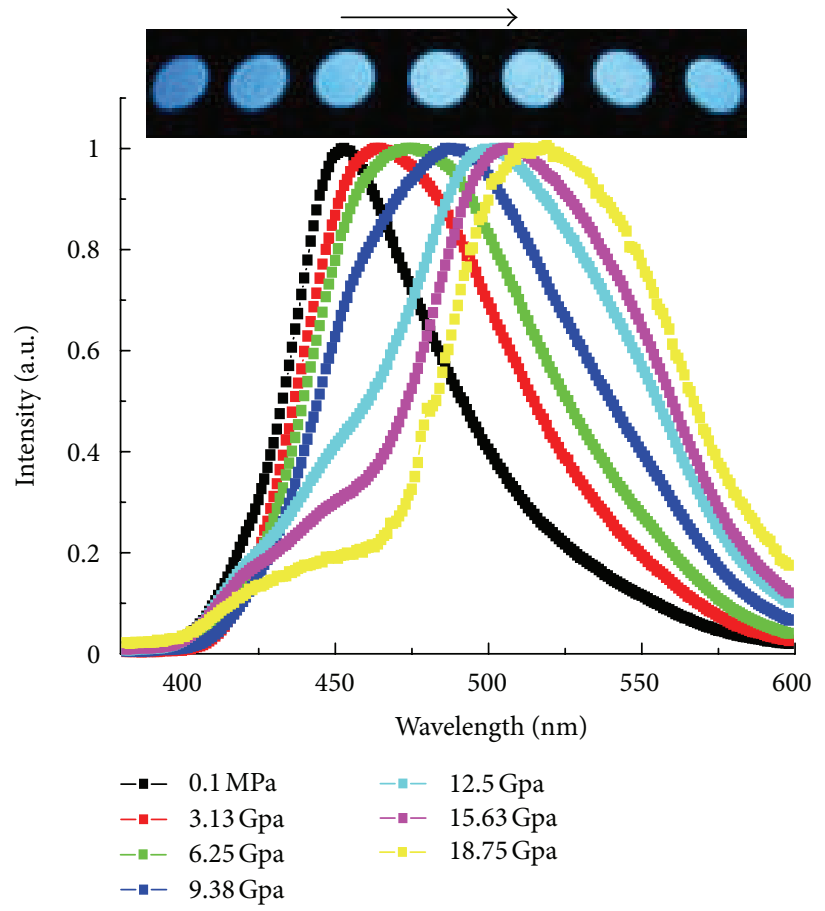

(a)

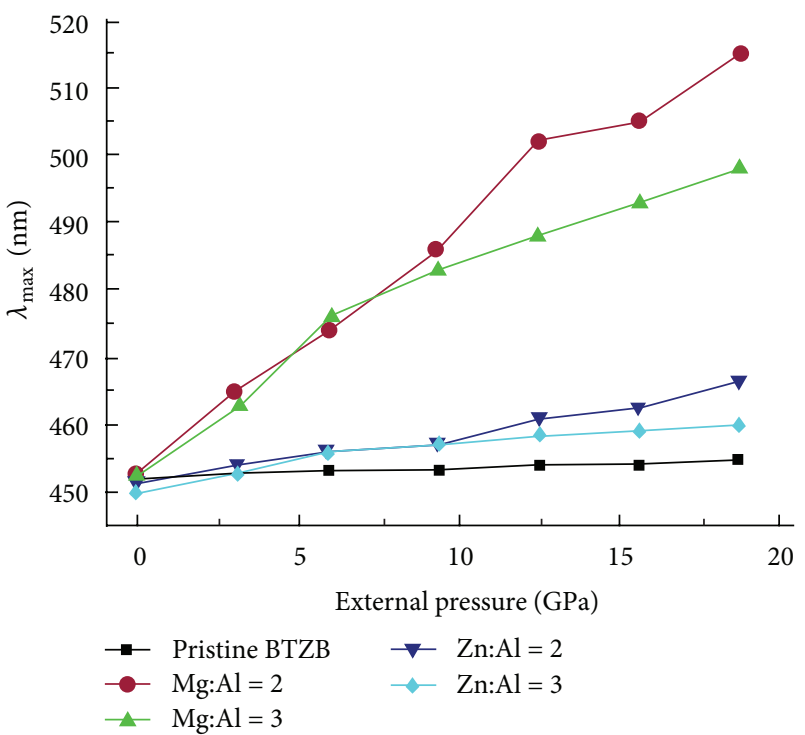

(b)

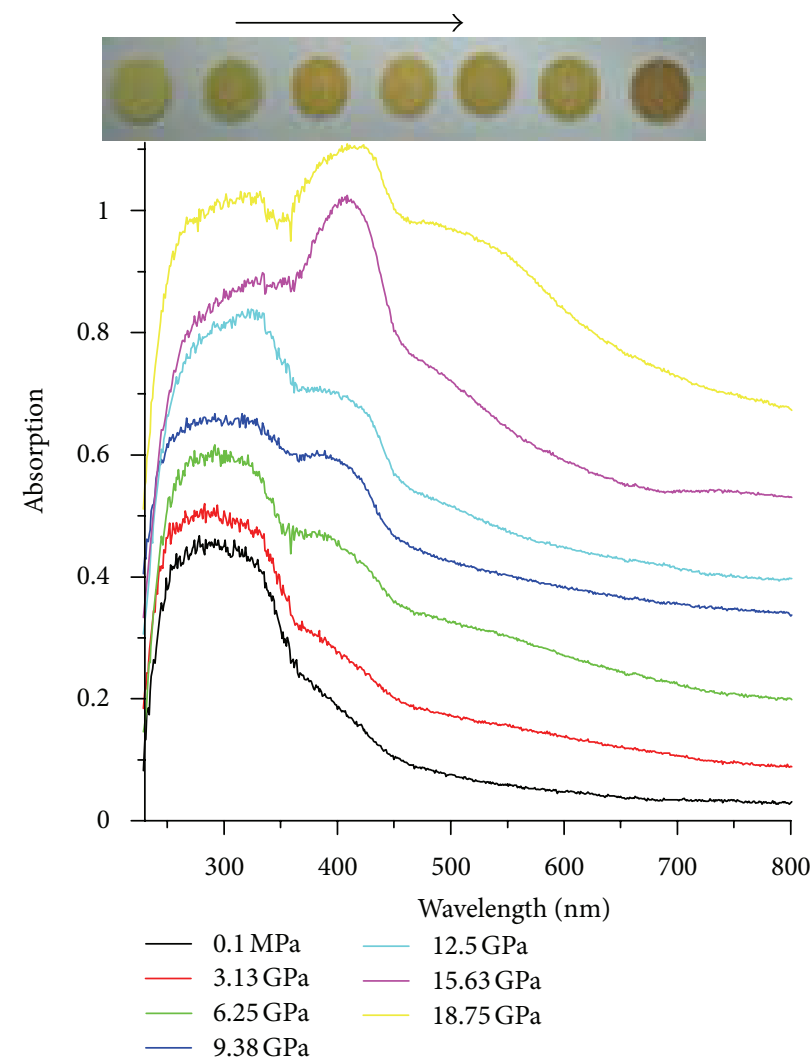

(c)

FIGURE 6: (a) Fluorescent spectra of the BTZB/Mg $\mathrm{Al}-\mathrm{LDH}$ at different pressures (inset: fluorescent photographs under $365 \mathrm{~nm}$ UV light; the arrow shows the direction of the increasing pressure); (b) maximum emissive wavelength of BTZB/LDHs at different pressures; (c) UV-vis spectra of the $\mathrm{BTZB} / \mathrm{Mg}_{2} \mathrm{Al}-\mathrm{LDH}$ at different pressures [33]. 
<smiles>Cc1ccc([S+](=O)([O-])c2ccc(C)cc2)cc1</smiles><smiles>CC1(C)C(/C=C/c2cc([N+](=O)[O-])ccc2[O-])=Nc2ccccc2C1(C)C</smiles><smiles></smiles>

Figure 7: Possible mechanism for reversible photoisomerization of MC in LDH [40].

nanogallery can also influence the surface properties based on the photoisomerization. For example, Chen et al. [42] have fabricated a hybrid film with a fluorine-containing azobenzene within the LDH on a porous anodic alumina/aluminum substrate. Irradiation with UV light led to a switch in wettability of the film from superhydrophobic to hydrophilic as shown in Figure 8, and this process could be reversed by subsequent irradiation with visible light. Such behavior can be assigned to the difference between the dipole moments of trans- and cis-azobenzene isomers: the film containing the more polar cis-isomer will become more hydrophilic, while the trans-isomer makes the surface hydrophobic.

Wang et al. [43] have fabricated optically transparent thin films with photochromic properties by means of cointercalation of azomethine- $\mathrm{H}$ anions (AMH) and 1-pentanesulfonate (PS) with different molar ratios into the nanogallery of a $\mathrm{Zn}$ Al-LDH. XRD and SEM show that the film exhibits welldefined c-axis orientation. Fluorescence spectra demonstrate that the sample with $2 \%$ AMH molar percentage, with respect to the total organic material, exhibits the optimal luminescent intensity. It was observed that the fluorescence lifetime of trans-keto tautomer in the $2 \% \mathrm{AMH}-\mathrm{LDH}$ film is shorter than that of AMH solution, indicating the trans-keto tautomer of $\mathrm{AMH}$ is less stable in the $2 \mathrm{D}$ confined environment, and the ground state of the enol tautomer is well stabilized in the LDH nanogallery. The results demonstrate an effective method for the preparation of photochromic thin film materials by co-intercalation of chromophore and dispersant into an inorganic 2D host matrix, which can be potentially applied in the field of photoelectronic devices.

2.3. Polarized and Electric-Induced Responsive Luminescence. The device with polarized emission can significantly enhance the quality of the back light of liquid-crystal displays [44, 45]. The LDH nanosheets with a 2D layered structure are intrinsically anisotropic; the luminescent guest with preferred orientation between LDH nanogallery can exhibit special anisotropic emission characteristics. Several examples have demonstrated that the ordered assembly of luminescent molecules into the $\mathrm{LDH}$ is undoubtedly favorable to produce a uniform orientation of transition dipole moment for polarized emission [12, 15, 46]. Based on the difference in the emissive colors of the chromophores at different polarization direction, it is possible to develop a new type of color-switching materials upon stimuli by polarized light. Recently, we have fabricated four types of heterogeneous multicolor luminescent UTF materials (blue/red, blue/yellow, blue/green, and red/green emission) by using different photofunctional anions [bis( $N$-methylacridinium)@polyvinylsulfonate ion pairs and anionic derivatives of $\operatorname{poly}(p-$ phenylene) (APPP), poly(phenylenevinylene) (APPV), and poly(thiophene) (APT)] and $\mathrm{LDH}$ nanosheets as building blocks [47]. The strategy for fabricating multicolor luminescent UTFs involves the stepwise assembly of individual luminescent species and $\mathrm{LDH}$ nanosheets. Therefore, 

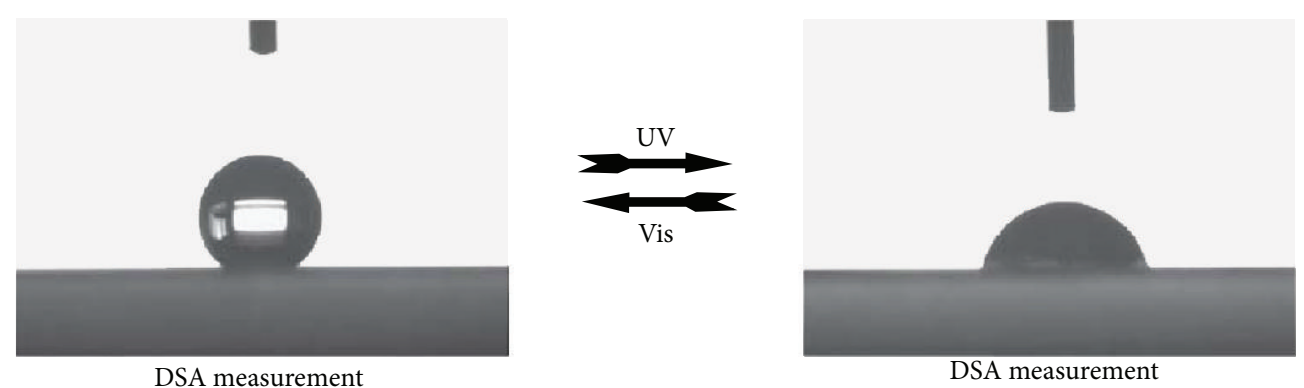

FIGURE 8: Shapes of a water droplet on the LDH hybrid film surface showing reversible superhydrophobicity and hydrophilicity induced by UV and visible irradiation [42].

the composition and loading of the luminescent species are finely controlled by adjusting the assembly sequence and cycle number, which is beneficial to the tunable multicolor emission. By changing the polarization direction of the two-color UTFs with a single excitation wavelength, it was observed that the intensity ratios for the two luminescence spectral regions were different, suggesting that the relative intensities of the two luminescence colors and the overall emission color are tuned by changing the polarization direction. For the (APPP/LDH $)_{12} /(\mathrm{APPV} / \mathrm{LDH})_{9} \mathrm{UTF}$, the ratio of the intensities of luminescence at 410 and $550 \mathrm{~nm}\left(I_{410} / I_{550}\right)$ was 1.25 for the $I_{\mathrm{VV}}$ polarization, while it was only 0.71 for the $I_{\mathrm{VH}}$ polarization (Figure 9(a)). For the $(\mathrm{APPP} / \mathrm{LDH})_{12} /(\mathrm{APT} / \mathrm{LDH})_{9} \mathrm{UTF}$, the intensity ratio $I_{410} / I_{575}$ had values of 1.65 ( $I_{\mathrm{VV}}$ polarization mode) and $0.94\left(I_{\mathrm{VH}}\right.$ polarization mode), respectively (Figure $\left.9(\mathrm{~b})\right)$. The variation in intensity ratio with polarization mode can be associated with the orientation and arrangement of the chromophores in the UTFs. We anticipate that these polarizedresponsive luminescent UTFs can act as a possible color conversion layer in flat-panel displays for future lighting devices.

From a stimuli-responsive perspective, the electroluminescence (EL) can be regarded as an electric-induced responsive luminescence behavior of device. Quantum dots (QDs), with their tunable photoluminescence and band gap, are expected to play an important role in future displays $[48,49]$. However, EL devices based on QDs have often suffered from relative low efficiency, short lifetimes, or the need of specialized deposition technique. Bendall et al. [50] have developed an all-inorganic EL device based on highly luminescent CdTe QD assembled LDH nanosheets by using a simple wet chemical process. The operating conditions were chosen to mimic the situation within an automotive environment, and the architecture of the device is shown in Figure 10. EL emission peak of the device is located at $637 \mathrm{~nm}$. Compared with the photoluminescence (PL) emission peak of the bare QD, no shift in the peak position is detected for the EL peak, and no significant change in the peak width occurs. Such evidence demonstrates that the emission is solely due to the CdTe QD. The advantage of this device is that the operating temperatures can be over $80^{\circ} \mathrm{C}$ due to the allinorganic materials. The authors believe the devices will have applications within harsh environments such as automobile lighting and entertainment or outdoor signaling. The ease of fabrication will also provide simple and low cost light sources.

\section{LDH-Based Chemical Stimuli-Responsive Properties}

3.1. pH-Responsive Luminescent Materials. The $\mathrm{pH}$ fluorescence chemosensors play critical roles in studying physiological activities influenced by $\mathrm{pH}$ value, widely used in fields of analytical chemistry, bioanalytical chemistry, cytobiology, and medical science $[53,54]$. The traditional solid host matrix (e.g., sol-gel polymer) has some inherent demerits, such as relatively poor thermal or optical stability as well as toxicity, which have limited the practical application in $\mathrm{pH}$ sensors to date. LDHs with a stable interlayer structure have highly enhanced the optical/thermal stability and environmental compatibility of the interlayer chromophore molecules and can be used as a new host matrix in more potential applications. Yan et al. [51] have fabricated a luminescent ordered UTF based on a anionic polythiophene (APT) and $\mathrm{Mg}$-Al-LDH nanosheets by the LBL assembly method. The dependence of the maximum emission wavelength $\left(\lambda_{\max }\right)$ on the $\mathrm{pH}$ value is divided into three main zones: the $\lambda_{\max }$ decreases sharply from 591 to $578 \mathrm{~nm}$ as the $\mathrm{pH}$ value is decreased from 14 to 12 ; it decreases very slightly from 578 to $574 \mathrm{~nm}$ when the $\mathrm{pH}$ value decreases from 12 to 8 ; finally, when the $\mathrm{pH}$ value is decreased from 8 to 4 , the $\lambda_{\max }$ undergoes a decrease from 574 to $562 \mathrm{~nm}$, which shows a nearly linear relationship with the $\mathrm{pH}$. The sensitivity of the fluorescence performance of the APT/LDH UTFs to $\mathrm{pH}$ value can be attributed to the varying extent of protonation and deprotonation of APT between the LDH nanosheets. Typical photographs of the luminescence of the UTF under two $\mathrm{pH}$ conditions are shown in the inset of Figure 11, from which it can be observed that the UTF shows bright red luminescence and a relatively dark orange color at $\mathrm{pH}=13$ and $\mathrm{pH}=$ 4 , respectively, under UV illumination. The APT/LDH UTF also exhibits reversible emissive response at different $\mathrm{pH}$ values, indicating its potential application as a $\mathrm{pH}$-sensitive luminescence sensor.

Base on the example above, it can be known that the selection of a suitable fluorescent compound with high response to $\mathrm{H}^{+}$in solution is of great importance for fabricating $\mathrm{pH}$-sensitive optical materials. Shi et al. [55] have reported 


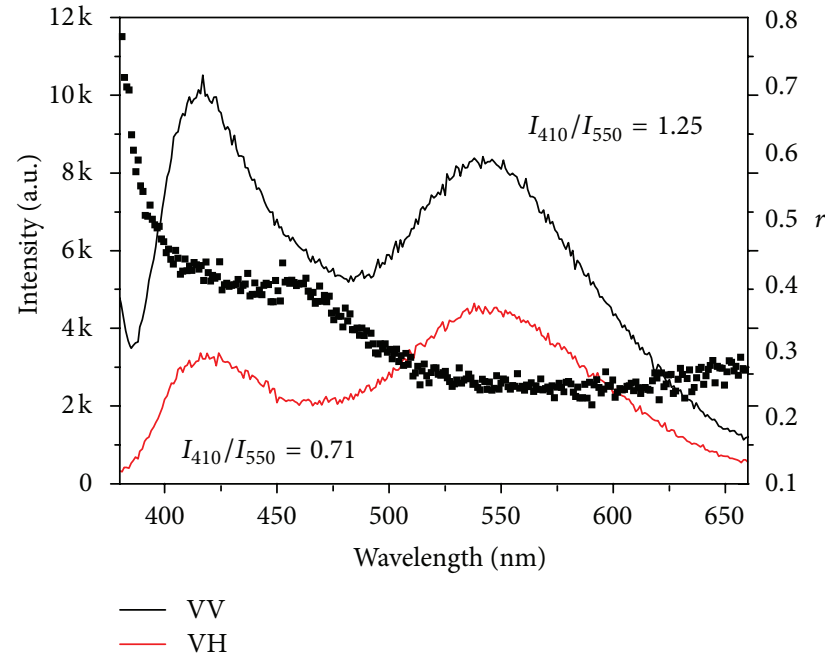

(a)

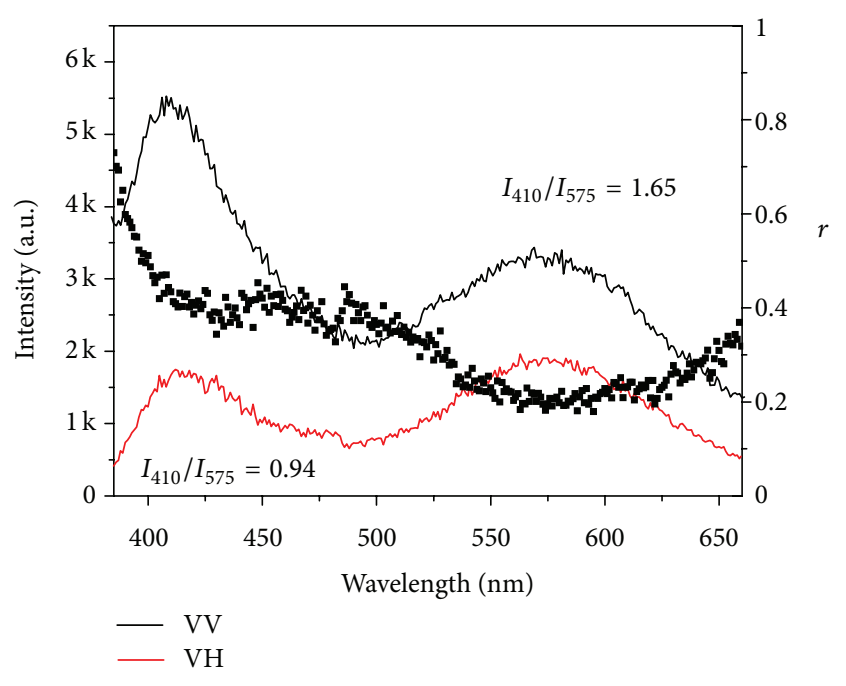

(b)

FIGURE 9: Polarized fluorescence profiles with glancing incidence geometry in the VV and VH modes and the anisotropy value $(r)$ for twocolor luminescent UTFs: (a) the (APPP/LDH $)_{12} /(\mathrm{APPV} / \mathrm{LDH})_{9} \mathrm{UTF}$; (b) the $(\mathrm{APPP} / \mathrm{LDH})_{12} /(\mathrm{APT} / \mathrm{LDH})_{9} \mathrm{UTF}[47]_{\text {. }}$

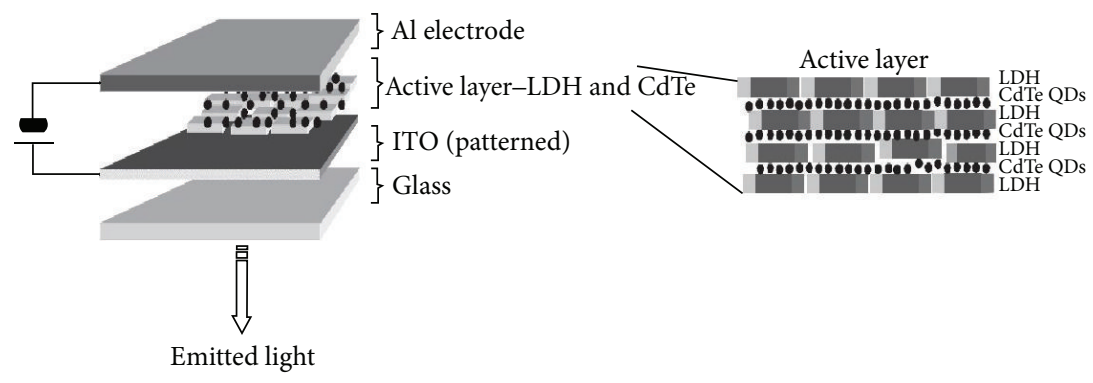

FIGURE 10: (a) Schematic of the architecture of the device, which is based on a "sandwich" structure with alternating LDH nanosheets and CdTe QDs [50].

a highly oriented photoluminescent film with film thickness of $300 \mathrm{~nm}$ based on the fluorescein and 1-heptanesulfonic acid sodium co-intercalated into LDH matrix. The film exhibits a broad linear dynamic range for solution with $\mathrm{pH}$ value from 5.02 to 8.54 . Good repeatability and reversibility have also been demonstrated: its relative standard deviation (RSD) is less than $1.5 \%$ in 20 consecutive cycles.

3.2. Metal Ion Responsive Luminescent Materials. The recognition of heavy metal ions (HMIs) is important in the fields of chemistry, biotechnology, medicine, and environmental science [56]. For instance, HMIs dispersed in an aqueous solution system (such as $\mathrm{Hg}^{2+}$ and $\mathrm{Cd}^{2+}$ ) can induce severe pollutions, which give rise to toxication and several diseases of organisms [57]. Thus, fast and effective detection of HMIs has drawn much attention from both scientific and engineering viewpoints during the last few years. The determination of HMIs has been generally carried out based on atomic absorption spectrometry [58] and inductively coupled plasma spectroscopy technique [59], which not only have good sensitivity and fast measurement capabilities, but also require expensive instruments, well-controlled experimental conditions, and complicated procedures. Due to the high sensitivity, selectivity, fast response, low cost, and easy signal detection, the fluorescence-based chemical analysis should be a good method for determining and monitoring contaminants. In this sense, organic luminescent molecules have recently become good candidates to detect the metal ion, based on the selective quenching effects of the metal ions in the solution of the luminescent molecules [60]. For example, Tao et al. [61] have reported that the synthesized $\pi$-conjugated polymer exhibits a selective fluorescence quenching by $\mathrm{Cu}^{2+}$. Cao et al. [62] found that a metal-organic framework powder exhibited fluorescence quenching by the solutions of HMIs. To date, most of the reported organic luminescence systems used for detecting metal ions are in the form of solution or powder systems, whereas this is unfavorable for its facile manipulation and cycling utility. Moreover, most of the luminescent dye solutions can induce environmental pollution and even operational risk, which are detrimental to human health. Therefore, there continues to be a challenge to develop new types of solid luminescent film systems to meet 


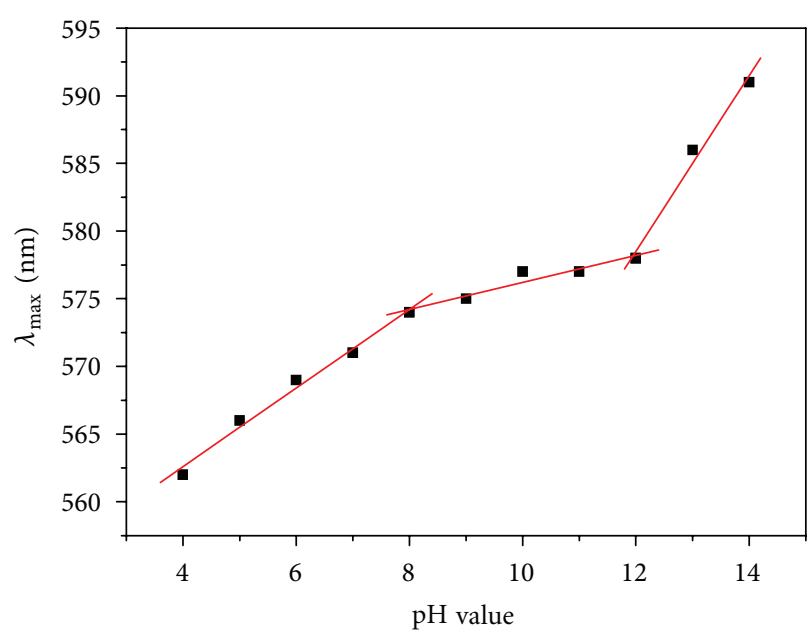

(a)

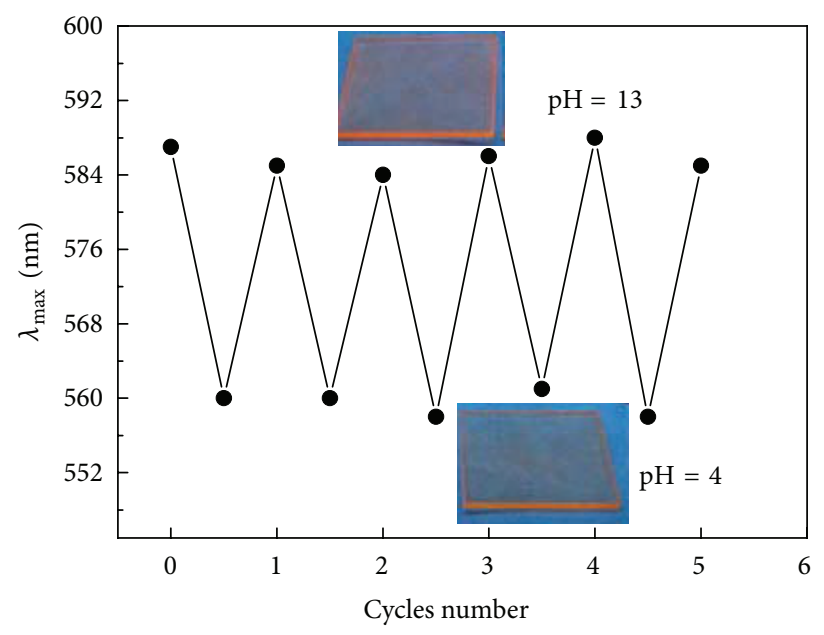

(b)

FIGURE 11: (a) Variation of the maximum photoemission wavelength of the APT/LDH film with different pH values; (b) the reversible photoemission response upon alternation between $\mathrm{pH}=4$ and $\mathrm{pH}=13$ (the inset show the luminescence photographs of the film at the two $\mathrm{pH}$ conditions) [51].

the need for the integration of high selectivity for the HMIs and efficient manipulation.

Mercury is considered one of the most toxic elements which are widely distributed in air, water, and soil $[63,64]$. As a consequence of this pollution, mercury can accumulate in the human body, which causes a wide variety of diseases, even in a low concentration, such as digestive, kidney, and neurological disorders. Sun et al. [65] have reported that an optical thin film can serve as chemosensor based on 1-amino-8-naphthol-3,6-disulfonic acid sodium ( $\mathrm{H}$-acid) intercalated $\mathrm{LDH}$. The $\mathrm{H}$-acid/LDH film chemosensor was immersed into $\mathrm{Hg}^{2+}$ aqueous solutions with different concentrations at $\mathrm{pH}$ value 7.0 for $10 \mathrm{~min}$ then was washed thoroughly, and dried at $60^{\circ} \mathrm{C}$ for $20 \mathrm{~min}$. It was found that the fluorescence intensity increases at first to a maximum and then decreases along with the increase of $\mathrm{pH}$ value. With the presence of other metal ions and common anions $\left(\mathrm{Cr}^{3+}, \mathrm{Mn}^{2+}, \mathrm{Co}^{2+}, \mathrm{Ni}^{2+}, \mathrm{Cu}^{2+}, \mathrm{Zn}^{2+}, \mathrm{Ag}^{+}, \mathrm{Cd}^{2+}\right.$, $\mathrm{Mg}^{2+}, \mathrm{Ca}^{2+}, \mathrm{Li}^{+}, \mathrm{Na}^{+}, \mathrm{K}^{+}, \mathrm{Al}^{3+}, \mathrm{Pb}^{2+}, \mathrm{Cl}^{-}$, and $\mathrm{NO}_{3}{ }^{-}$), which are possible competitive ions in practical determination, the results show no significant effect on the results, demonstrating a strong resistance to interference. This film can be potentially used as a chemosensor for the detection of $\mathrm{Hg}^{2+}$ ion in the environmental and biological field. Yan et al. [66] have prepared the UTFs with blue luminescence based on a styrylbiphenyl derivative (BTBS) and Mg-Al-LDH nanosheets. The luminescence spectra of the (BTBS-LDH) $)_{32}$ UTF measured after immersing it in different metal cationic aqueous solutions $\left(\mathrm{Hg}^{2+}, \mathrm{Cu}^{2+}, \mathrm{Pb}^{2+}, \mathrm{Cd}^{2+}, \mathrm{Cr}^{3+}, \mathrm{Ca}^{2+}\right.$, $\mathrm{Mn}^{2+}, \mathrm{Co}^{2+}, \mathrm{Zn}^{2+}$, and $\mathrm{Fe}^{3+}$ ) with varying concentrations (from $10^{-5}$ to $10^{-2} \mathrm{M}$ ) showed the fluorescence intensity of the UTF decreases systematically upon increasing the ion concentration, and the $\mathrm{Hg}^{2+}$ has the most significant effect on the luminescence quenching of the UTFs with a detection limit of $2.3 \times 10^{-7} \mathrm{~mol} \cdot \mathrm{L}^{-1}$. After the UTF was treated with $0.01 \mathrm{M}$ EDTA aqueous solution for $30 \mathrm{~s}$, followed by thorough washing and drying, the fluorescence intensity can nearly recover to its initial state with 5 cycles at least.

Magnesium ion, being the most abundant intracellular divalent cation, plays a major role in many cellular processes including stabilization of DNA conformation, ion transport through the membrane, and signal transduction. Additionally, the activity of magnesium in blood and serum is an important clinical parameter that needs to be monitored in different situations. All these provide sufficient impetus to fabricate chemical sensors for the detection of magnesium $[67,68]$. Jin et al. [69] have prepared a 8-aminonaphthalene1,3,6-trisulfonate (ANTS)/LDH fluorescent film by an electrophoretic deposition (EPD) method. The ANTS/LDH film shows a good fluorescent response for $\mathrm{Mg}^{2+}$ ion. In addition, the linear correlation $\left(R^{2}\right)$ between the fluorescence intensity of the ANTS/LDH and the concentration of $\mathrm{Mg}^{2+}$ is 0.996 , with a detection limit of $2.37 \times 10^{-7} \mathrm{M}$. The results exhibited that ANTS/LDH film has a considerable fluorescence selectivity for $\mathrm{Mg}^{2+}$ ions, with no significant response to other metal ions $\left(\mathrm{Ca}^{2+}, \mathrm{Na}^{+}, \mathrm{K}^{+}, \mathrm{Fe}^{3+}, \mathrm{Co}^{2+}, \mathrm{Ni}^{2+}\right.$, or $\left.\mathrm{Cu}^{2+}\right)$, which indicated a high fluorescence selectivity for $\mathrm{Mg}^{2+}$ ions.

Compared with intensity-based sensors, ratiometric fluorescence systems are preferred in bioimaging applications because such measurement involves the change of intensity ratio of emission at two wavelengths, which eliminates interferences from environment and increases the selectivity and sensitivity effectively. For example, Ji et al. [52] have built a fluorescence sensor for $\mathrm{Be}^{2+}$ with high selective response by alternate assembly of Beryllon II and Mg-Al-LDH nanosheets on quartz substrates using the LBL deposition technique. The Beryllon II/LDH UTFs displays ratiometric fluorescence response for $\mathrm{Be}^{2+}$ (Figure 12(a)) with a linear response range in $1.0 \times 10^{-7}-1.9 \times 10^{-6} \mathrm{~mol} \cdot \mathrm{L}^{-1}$ and a detection limit of 


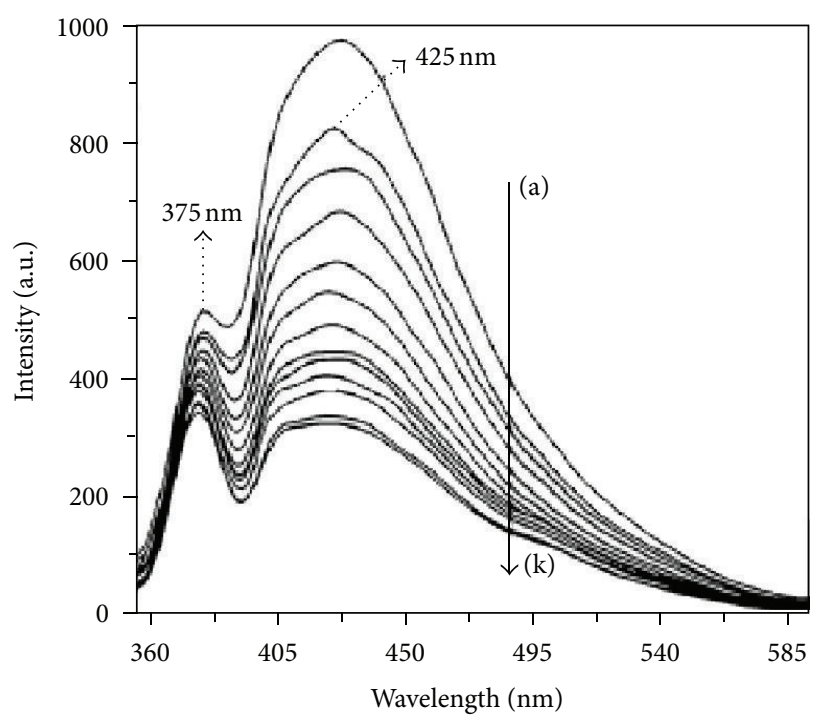
(a) $\left[\mathrm{Be}^{2+}\right]=0 \mu \mathrm{m}$
(g) $\left[\mathrm{Be}^{2+}\right]=1.1 \mu \mathrm{m}$
(b) $\left[\mathrm{Be}^{2+}\right]=0.1 \mu \mathrm{m}$
(h) $\left[\mathrm{Be}^{2+}\right]=1.3 \mu \mathrm{m}$
(c) $\left[\mathrm{Be}^{2+}\right]=0.3 \mu \mathrm{m}$
(i) $\left[\mathrm{Be}^{2+}\right]=1.5 \mu \mathrm{m}$
(d) $\left[\mathrm{Be}^{2+}\right]=0.5 \mu \mathrm{m}$
(j) $\left[\mathrm{Be}^{2+}\right]=1.7 \mu \mathrm{m}$
(e) $\left[\mathrm{Be}^{2+}\right]=0.7 \mu \mathrm{m}$
(k) $\left[\mathrm{Be}^{2+}\right]=1.9 \mu \mathrm{m}$
(f) $\left[\mathrm{Be}^{2+}\right]=0.9 \mu \mathrm{m}$
(l) $\left[\mathrm{Be}^{2+}\right]=2.1 \mu \mathrm{m}$
(m) $\left[\mathrm{Be}^{2+}\right]=2.3 \mu \mathrm{m}$

(a)

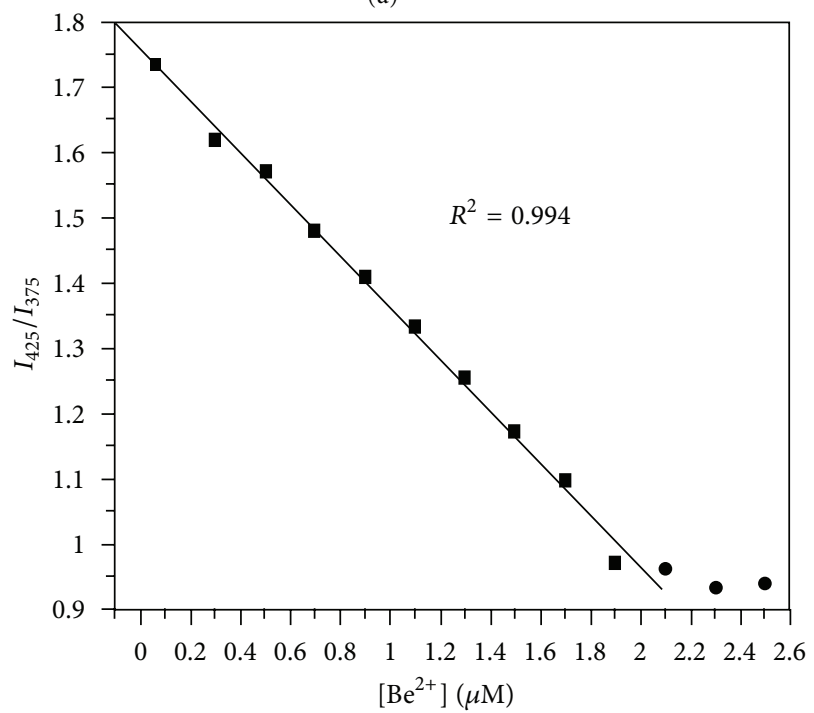

(b)

FIGURE 12: (a) Emission spectra of the (Beryllon II/LDH) $)_{20}$ UTF upon increasing Be $\mathrm{e}^{2+}$ concentration at $\mathrm{pH}=11$; (b) $\mathrm{Be}^{2+}$ titration curve of the chemosensor for emission ratio at $425-375 \mathrm{~nm}\left(I_{425} / I_{375}\right)[52]$.

$4.2 \times 10^{-9} \mathrm{~mol} \cdot \mathrm{L}^{-1}$ (Figure 12(b)). Evaluated with other competitive species $\left(\mathrm{Zn}^{2+}, \mathrm{Al}^{3+}, \mathrm{Co}^{2+}, \mathrm{Mg}^{2+}, \mathrm{Cd}^{2+}, \mathrm{Ca}^{2+}, \mathrm{Hg}^{2+}\right.$, $\mathrm{Cu}^{2+}, \mathrm{Pb}^{2+}, \mathrm{Ni}^{2+}$, and $\mathrm{Mn}^{2+}$ ), the Beryllon II/LDH UTF displays a good selectivity towards $\mathrm{Be}^{2+}$. A high thermodynamic affinity of $\mathrm{Be}^{2+}$ toward typical $\mathrm{N}$ and S-chelate ligands and fast metal-to-ligand binding kinetics lead to the complexation of $\mathrm{Be}^{2+}$ with Beryllon II in the UTF, which is the result of fluorescence quenching.

\section{Conclusions and Outlook}

The assembly of photoactive chromophore within the nanogallery of $\mathrm{LDH}$ can provide a facile way to develop new types of stimuli-responsive materials with host-guest structures, which also present enhanced properties (such as high photo-/optical stability and good operability). By designing and choosing the suitable photoactive chromophores and $\mathrm{LDH}$ layers as basic building blocks, these organic-inorganic 
hybrid nanomaterials (ultrathin films and nanocomposites) have presented promising applications in the field of switches of piezochromic, photochromic, thermochromic, and polarized luminescence as well as $\mathrm{pH} /$ metal sensors. To meet the need of practical application, further studies should be put in how to finely regular and control the arrangement and orientation of the guest chromophore and how to maintain the uniform and ordered thin film system. In addition, challenges for stimuli-responsive host-guest materials include how to further enhance the photo-/thermoisomerization efficiency and repeatability. Moreover, despite several researches on single-stimulus-responsive property of such materials, development on multistimuli-responsive smart materials still remains in its fancy and has been very seldom studied. This can be an important strategy and direction to develop multifunctional materials. Last but not least, the response time and on/off ratio of these switches and sensors for realtime applications should also be taken in account in next step researches.

\section{Acknowledgments}

This work was supported by the National Natural Science Foundation of China, the 973 Program (Grant no. 2011CBA00504), 111 Project (Grant no. B07004), and Program for Changjiang Scholars and Innovative Research Team in University (PCSIRT: IRT1205).

\section{References}

[1] M. Irie, T. Fukaminato, T. Sasaki, N. Tamai, and T. Kawai, "A digital fluorescent molecular photoswitch," Nature, vol. 420, no. 6917, pp. 759-760, 2002.

[2] C. Löwe and C. Weder, "Oligo(p-phenylene vinylene) excimers as molecular probes: deformation-induced color changes in photoluminescent polymer blends," Advanced Materials, vol. 14, no. 22, pp. 1625-1629, 2002.

[3] T. Mutai, H. Tomoda, T. Ohkawa, Y. Yabe, and K. Araki, "Switching of polymorph-dependent ESIPT luminescence of an imidazo[1,2-a]pyridine derivative," Angewandte ChemieInternational Edition, vol. 120, no. 49, pp. 9664-9666, 2008.

[4] J. Kunzelman, M. Kinami, B. R. Crenshaw, J. D. Protasiewicz, and C. Weder, "Oligo(p-phenylene vinylene)s as a "new" class of piezochromic fluorophores," Advanced Materials, vol. 20, no. 1, pp. 119-122, 2008.

[5] T. Fukaminato and M. Irie, "Reversible fluorescence wavelength shift based on photoinduced aggregate formation," Advanced Materials, vol. 18, no. 24, pp. 3225-3228, 2006.

[6] N. Chandrasekharan and L. A. Kelly, "A dual fluorescence temperature sensor based on perylene/exciplex interconversion," Journal of the American Chemical Society, vol. 123, no. 40, pp. 9898-9899, 2001.

[7] J. Kunzelman, B. R. Crenshaw, and C. Weder, "Self-assembly of chromogenic dyes-a new mechanism for humidity sensors," Journal of Materials Chemistry, vol. 17, no. 29, pp. 2989-2991, 2007.

[8] C. Xia and R. C. Advincula, "Decreased aggregation phenomena in polyfluorenes by introducing carbazole copolymer units," Macromolecules, vol. 34, no. 17, pp. 5854-5859, 2001.
[9] V. Rives, Layered Double Hydroxides: Present and Future, Nova Science, New York, NY, USA, 2001.

[10] F. Li and X. Duan, "Applications of layered double hydroxide," Structure and Bonding, vol. 119, pp. 193-223, 2006.

[11] S. P. Newman and W. Jones, "Synthesis, characterization and applications of layered double hydroxides containing organic guests," New Journal of Chemistry, vol. 22, no. 2, pp. 105-115, 1998.

[12] D. P. Yan, J. Lu, M. Wei, D. G. Evans, and X. Duan, "Sulforhodamine B intercalated layered double hydroxide thin film with polarized photoluminescence," Journal of Physical Chemistry B, vol. 113, no. 5, pp. 1381-1388, 2009.

[13] D. P. Yan, J. Lu, J. Ma, M. Wei, D. G. Evans, and X. Duan, "Benzocarbazole anions intercalated layered double hydroxide and its tunable fluorescence," Physical Chemistry Chemical Physics, vol. 12, no. 45, pp. 15085-15092, 2010.

[14] W. Shi, M. Wei, J. Lu et al., "Molecular orientation and fluorescence studies on naphthalene acetate intercalated $\mathrm{Zn}_{2} \mathrm{Al}$ layered double hydroxide," Journal of Physical Chemistry C, vol. 112, no. 50, pp. 19886-19895, 2008.

[15] D. P. Yan, J. Lu, M. Wei et al., "Poly(p-phenylene) anionic derivative/layered double hydroxides ordered ultra thin films with blue luminescence by layer-by-layer assembly," Angewandte Chemie-International Edition, vol. 48, no. 17, pp. 3073-3076, 2009.

[16] D. P. Yan, J. Lu, J. Ma et al., "Anionic poly(p-phenylenevinylene)/layered double hydroxide ordered ultrathin films with multiple quantum well structure: a combined experimental and theoretical study," Langmuir, vol. 26, no. 10, pp. 7007-7014, 2010.

[17] S. Li, J. Lu, M. Wei, D. G. Evans, and X. Duan, "Tris(8hydroxyquinoline-5-sulfonate)aluminum intercalated $\mathrm{Mg}$-Al layered double hydroxide with blue luminescence by hydrothermal synthesis," Advanced Functional Materials, vol. 20, no. 17, pp. 2848-2856, 2010.

[18] D. P. Yan, J. Lu, M. Wei, J. Ma, D. G. Evans, and X. Duan, "A combined study based on experiment and molecular dynamics: perylene tetracarboxylate intercalated in a layered double hydroxide matrix," Physical Chemistry Chemical Physics, vol. 11, no. 40, pp. 9200-9209, 2009.

[19] D. P. Yan, J. Lu, M. Wei, D. G. Evans, and X. Duan, "Recent advances in photofunctional guest/layered double hydroxide host composite systems and their applications: experimental and theoretical perspectives," Journal of Materials Chemistry, vol. 21, pp. 13128-13139, 2011.

[20] I. McCulloch, M. Heeney, C. Bailey et al., "Liquid-crystalline semiconducting polymers with high charge-carrier mobility," Nature Materials, vol. 5, no. 4, pp. 328-333, 2006.

[21] M. A. Thyveetil, P. V. Coveney, H. C. Greenwell, and J. L. Suter, "Role of host layer flexibility in DNA guest intercalation revealed by computer simulation of layered nanomaterials," Journal of the American Chemical Society, vol. 130, no. 37, pp. 12485-12495, 2008.

[22] L. Tian, F. He, H. Zhang et al., "Thermal cycloaddition facilitated by orthogonal $\pi-\pi$ organization through conformational transfer in a swivel-cruciform oligo (phenylenevinylene)," Angewandte Chemie-International Edition, vol. 46, no. 18, pp. 3245-3248, 2007.

[23] H. Meier, "Conjugated oligomers with terminal donor-acceptor substitution," Angewandte Chemie-International Edition, vol. 44, no. 17, pp. 2482-2506, 2005.

[24] D. P. Yan, J. Lu, M. Wei, J. Ma, D. G. Evans, and X. Duan, "Reversibly thermochromic, fluorescent ultrathin films 
with a supramolecular architecture," Angewandte ChemieInternational Edition, vol. 50, no. 3, pp. 720-723, 2011.

[25] X. Wang, J. Lu, W. Shi et al., "A thermochromic thin film based on host-guest interactions in a layered double hydroxide," Langmuir, vol. 26, no. 2, pp. 1247-1253, 2010.

[26] M. Inouye, K. Tsuchiya, and T. Kitao, "New thermo-response dyes: coloration by the claisen rearrangement and intramolecular acid-base reaction," Angewandte Chemie-International Edition, vol. 31, no. 2, pp. 204-205, 1992.

[27] A. Sarkar, S. Okada, H. Matsuzawa, H. Matsuda, and H. Nakanishi, "Novel polydiacetylenes for optical materials: beyond the conventional polydiacetylenes," Journal of Materials Chemistry, vol. 10, no. 4, pp. 819-828, 2000.

[28] H. J. Cho, K. Seo, C. J. Lee, H. Yun, and J. Y. Chang, "Rodlike mesogenic molecules consisting of two diacetylenic groups: mesomorphic behavior and photoimaging," Journal of Materials Chemistry, vol. 13, no. 5, pp. 986-990, 2003.

[29] W. Y. Shi, Y. J. Lin, S. He et al., "Patterned fluorescence films with reversible thermal response based on the host-guest superarchitecture," Journal of Materials Chemistry, vol. 21, pp. 11116-11122, 2011.

[30] Z. G. Chi and J. R. Xu, "New thermally stable piezofluorochromic aggregation-induced emission compounds," Organic Letters, vol. 13, no. 4, pp. 556-559, 2011.

[31] X. Zhang, Z. Chi, H. Li et al., "Piezofluorochromism of an aggregation-induced emission compound derived from tetraphenylethylene," Chemistry, vol. 6, no. 3, pp. 808-811, 2011.

[32] Z. Chi, X. Zhang, B. Xu et al., "Recent advances in organic mechanofluorochromic materials," Chemical Society Reviews, vol. 41, no. 10, pp. 3878-3896, 2012.

[33] D. P. Yan, J. Lu, J. Ma et al., "Layered host-guest materials with reversible piezochromic luminescence," Angewandte ChemieInternational Edition, vol. 50, no. 31, pp. 7037-7040, 2011.

[34] J. Zhang, Q. Zou, and H. Tian, "Photochromic materials: more than meets the eye," Advanced Materials, vol. 25, no. 3, pp. 378399, 2012.

[35] T. F. Tan, P. L. Chen, H. M. Huang, and J. B. Meng, "Synthesis, characterization and photochromic studies in film of heterocycle-containing spirooxazines," Tetrahedron, vol. 61, no. 34, pp. 8192-8198, 2005.

[36] H. Durr, "Perspective in photochromism-based on the 15-eleetroeyclization of heteroanalogous pentadienyl anions," Angewandte Chemie-International Edition, vol. 28, pp. 413431, 1989.

[37] E. H. Kang, T. Bu, P. Jin, J. Sun, Y. Yang, and J. Shen, "Layer-by-layer deposited organic/inorganic hybrid multilayer films containing noncentrosymmetrically orientated azobenzene chromophores," Langmuir, vol. 23, no. 14, pp. 7594-7601, 2007.

[38] H. Tagaya, T. Kuwahara, S. Sato, J. I. Kadokawa, M. Karasu, and K. Chiba, "Photoisomerization of indolinespirobenzopyran in layered double hydroxides," Journal of Materials Chemistry, vol. 3, no. 3, pp. 317-318, 1993.

[39] T. Kuwahara, H. Tagaya, and K. Chiba, "Photochromism of spiropyran dye in Li-Al layered double hydroxide," Microporous Materials, vol. 4, no. 2-3, pp. 247-250, 1995.

[40] H. Tagaya, S. Sato, T. Kuwahara, J. I. Kadokawa, K. Masa, and K. Chiba, "Photoisomerization of indolinespirobenzopyran in anionic clay matrices of layered double hydroxides," Journal of Materials Chemistry, vol. 4, no. 12, pp. 1907-1912, 1994.
[41] J. B. Han, D. P. Yan, W. Y. Shi et al., "Layer-by-layer ultrathin films of azobenzene-containing polymer/layered double hydroxides with reversible photoresponsive behavior," Journal of Physical Chemistry B, vol. 114, no. 17, pp. 5678-5685, 2010.

[42] T. Chen, S. Xu, F. Zhang, D. G. Evans, and X. Duan, "Formation of photo- and thermo-stable layered double hydroxide films with photo-responsive wettability by intercalation of functionalized azobenzenes," Chemical Engineering Science, vol. 64, no. 21, pp. 4350-4357, 2009.

[43] X. R. Wang, J. Lu, D. P. Yan, M. Wei, D. G. Evans, and X. Duan, "A photochromic thin film based on salicylideneaniline derivatives intercalated layered double hydroxide," Chemical Physics Letters, vol. 493, no. 4-6, pp. 333-339, 2010.

[44] C. Weder, C. Sarwa, A. Montali, C. Bastiaansen, and P. Smith, "Incorporation of photoluminescent polarizers into liquid crystal displays," Science, vol. 279, no. 5352, pp. 835-837, 1998.

[45] B. Zhou, Y. Lin, L. Monica Veca, K. A. Shiral Fernando, B. A. Harruff, and Y. P. Sun, "Luminescence polarization spectroscopy study of functionalized carbon nanotubes in a polymeric matrix," Journal of Physical Chemistry B, vol. 110, no. 7, pp. 3001-3006, 2006.

[46] D. P. Yan, S. Qin, L. Chen et al., "Thin film of sulfonated zinc phthalocyanine/layered double hydroxide for achieving multiple quantum well structure and polarized luminescence," Chemical Communications, vol. 46, no. 45, pp. 8654-8656, 2010.

[47] D. P. Yan, J. Lu, M. Wei et al., "Heterogeneous transparent ultrathin films with tunable-color luminescence based on the assembly of photoactive organic molecules and layered double hyroxides," Advanced Functional Materials, vol. 21, no. 13, pp. 2497-2505, 2011.

[48] G. Mingyuan, C. Lesser, S. Kirstein, E. Möhwald, A. L. Rogach, and $\mathrm{H}$. Weller, "Electroluminescence of different colors from polycation/CdTe nanocrystal self-assembled films," Journal of Applied Physics, vol. 87, no. 5, pp. 2297-2302, 2000.

[49] W. Chung, K. Park, H. J. Yu, J. Kim, B. H. Chun, and S. H. Kim, "White emission using mixtures of CdSe quantum dots and PMMA as a phosphor," Optical Materials, vol. 32, no. 4, pp. 515-521, 2010.

[50] J. S. Bendall, M. Paderi, F. Ghigliotti et al., "Layer-by-layer allinorganic quantum-dot-based LEDs: a simple procedure with robust performance," Advanced Functional Materials, vol. 20, no. 19, pp. 3298-3302, 2010.

[51] D. P. Yan, J. Lu, J. Ma, M. Wei, D. G. Evans, and X. Duan, "Fabrication of an anionic polythiophene/layered double hydroxide ultrathin film showing red luminescence and reversible $\mathrm{pH}$ photoresponse," AIChE Journal, vol. 57, no. 7, pp. 1926-1935, 2011.

[52] X. L. Ji, W. Y. Shi, S. T. Zhang, M. Wei, D. G. Evans, and X. Duan, "A ratiometric fluorescence sensor for $\mathrm{Be}^{2+}$ based on Beryllon II/layered double hydroxide ultrathin films," Analytica Chimica Acta, vol. 728, pp. 77-85, 2012.

[53] I. Roy and M. N. Gupta, "Smart polymeric materials: emerging biochemical applications," Chemistry \& Biology, vol. 10, no. 12, pp. 1161-1171, 2003.

[54] E. S. Gil and S. M. Hudson, "Stimuli-responsive polymers and their bio-conjugates," Progress in Polymer Science, vol. 29, no. 12, pp. 1173-1222, 2004.

[55] W. Y. Shi, S. He, M. Wei, D. G. Evans, and X. Duan, "Optical pH sensor with rapid response based on a fluorescein-intercalated layered double hydroxide," Advanced Functional Materials, vol. 20, no. 22, pp. 3856-3863, 2010. 
[56] H. N. Kim, Z. Guo, W. Zhu, J. Yoon, and H. Tian, "Recent progress on polymer-based fluorescent and colorimetric chemosensors," Chemical Society Reviews, vol. 40, no. 1, pp. 79-93, 2011.

[57] S. Yoon, E. W. Miller, Q. He, P. H. Do, and C. J. Chang, "A bright and specific fluorescent sensor for mercury in water, cells, and tissue," Angewandte Chemie-International Edition, vol. 46, no. 35, pp. 6658-6661, 2007.

[58] J. V. Cizdziel and S. Gerstenberger, "Determination of total mercury in human hair and animal fur by combustion atomic absorption spectrometry," Talanta, vol. 64, no. 4, pp. 918-921, 2004.

[59] S. C. Hight and J. Cheng, "Determination of methylmercury and estimation of total mercury in seafood using high performance liquid chromatography (HPLC) and inductively coupled plasma-mass spectrometry (ICP-MS): method development and validation," Analytica Chimica Acta, vol. 567, no. 2, pp. 160$172,2006$.

[60] M. Wang, G. Zhang, D. Zhang, D. Zhu, and B. Z. Tang, "Fluorescent bio/chemosensors based on silole and tetraphenylethene luminogens with aggregation-induced emission feature," Journal of Materials Chemistry, vol. 20, no. 10, pp. 1858-1867, 2010.

[61] X. Tao, Y. Liu, and K. S. Schanze, "A conjugated polyelectrolytebased fluorescence sensor for pyrophosphate," Chemical Communications, no. 28, pp. 2914-2916, 2007.

[62] Y. Cao, Y. Cui, Q. Zheng, S. Xiang, G. Qian, and B. Chen, “A microporous luminescent metal-organic framework for highly selective and sensitive sensing of $\mathrm{Cu}^{2+}$ in aqueous solution," Chemical Communications, vol. 46, no. 30, pp. 5503-5505, 2010.

[63] I. Onyido, A. R. Norris, and E. Buncel, "Biomolecule-mercury interactions: modalities of DNA base-mercury binding mechanisms. Remediation strategies," Chemical Reviews, vol. 104, no. 12, pp. 5911-5929, 2004.

[64] N. S. Bloom, A. K. Grout, and E. M. Prestbo, "Development and complete validation of a method for the determination of dimethyl mercury in air and other media," Analytica Chimica Acta, vol. 546, no. 1, pp. 92-101, 2005.

[65] Z. Y. Sun, L. Jin, S. T. Zhang et al., "An optical sensor based on Hacid/layered double hydroxide composite film for the selective detection of mercury ion," Analytica Chimica Acta, vol. 702, no. 1, pp. 95-101, 2011.

[66] D. P. Yan, J. Lu, M. Wei, D. G. Evans, and X. Duan, "Luminescent ultrathin film of the anionic styrylbiphenyl derivatives/layered double hydroxide and its reversible sensing for heavy metal ions," Physical Chemistry Chemical Physics, vol. 14, no. 24, pp. 8591-8598, 2012.

[67] M. Ishida, Y. Naruta, and F. Tani, "A Porphyrin-related macrocycle with an embedded 1,10-phenanthroline moiety: fluorescent magnesium(II) ion sensor," Angewandte Chemie-International Edition, vol. 49, no. 1, pp. 91-94, 2010.

[68] J. L. Lopez, A. Tárraga, A. Espinosa et al., "A new multifunctional ferrocenyl-substituted ferrocenophane derivative: optical and electronic properties and selective recognition of $\mathrm{Mg}^{2+}$ ions," Chemistry, vol. 10, no. 7, pp. 1815-1826, 2004.

[69] L. Jin, Z. J. Guo, Z. Y. Sun, A. Li, Q. Jin, and M. Wei, "Assembly of 8-aminonaphthalene-1,3,6-trisulfonate intercalated layered double hydroxide film for the selective detection of $\mathrm{Mg}^{2+}$," Sensors and Actuators B, vol. 161, pp. 714-720, 2012. 

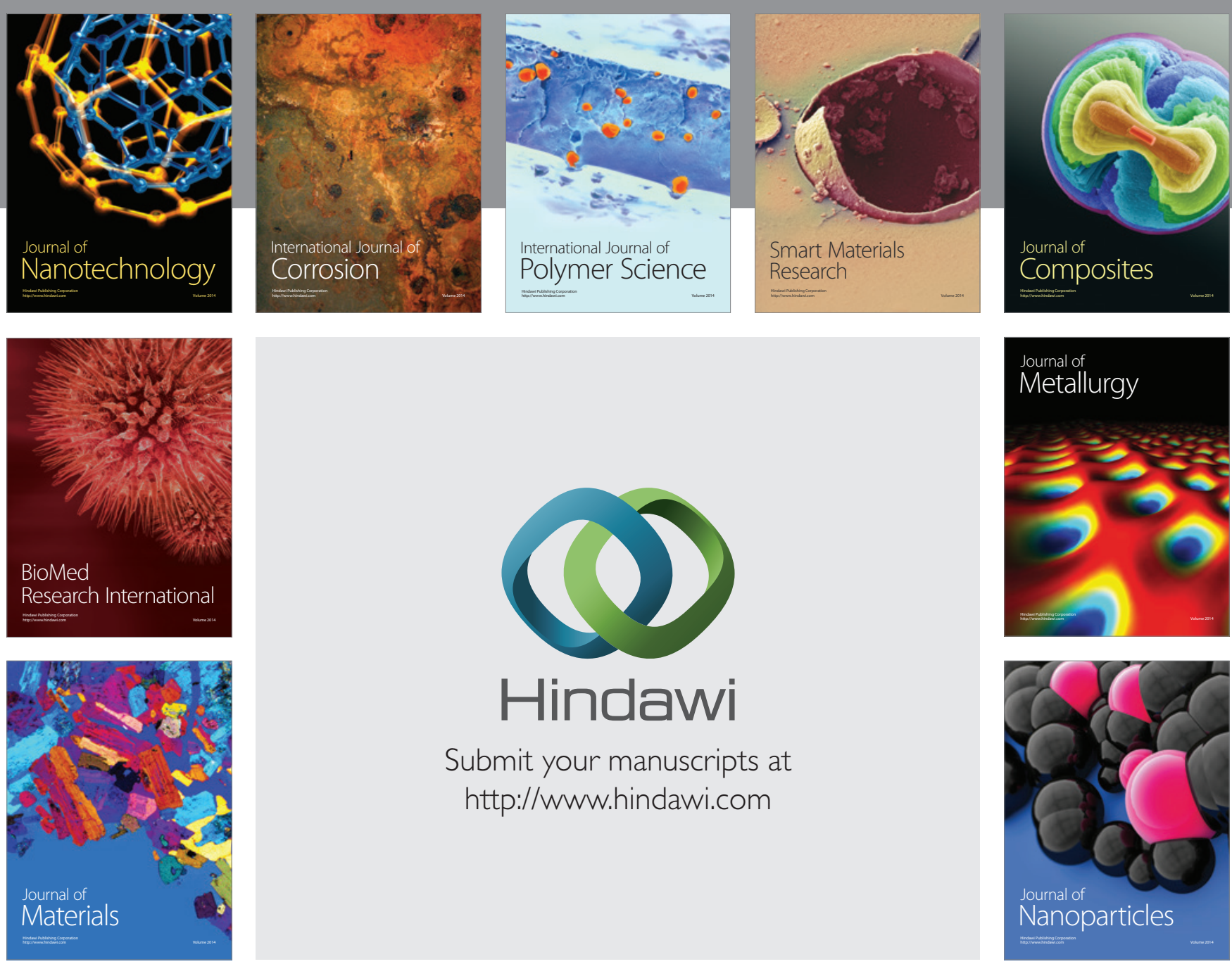

Submit your manuscripts at http://www.hindawi.com
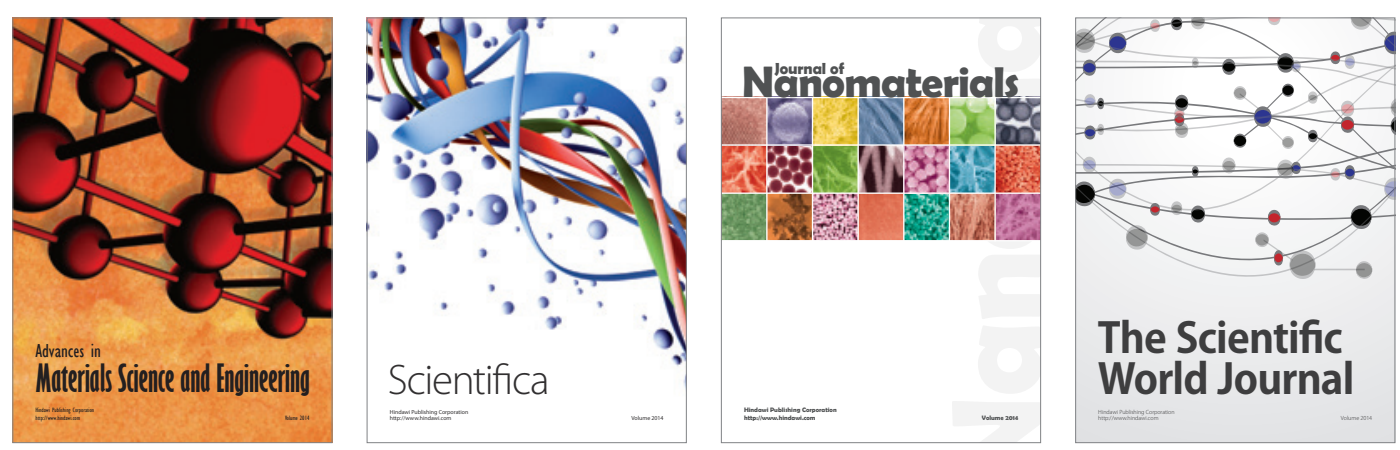

\section{The Scientific World Journal}
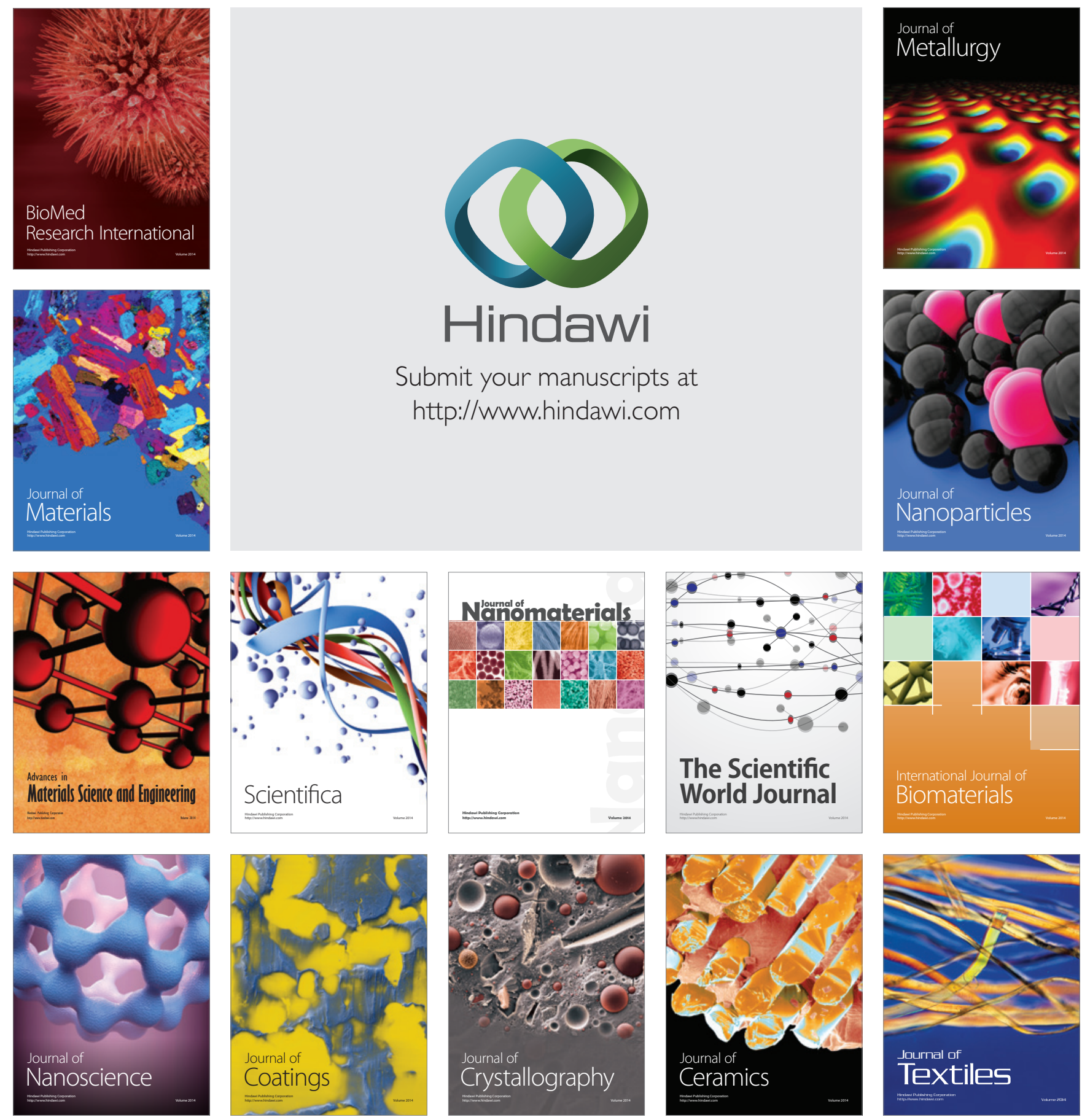